\title{
MASALAH TIDUR DAN STRATEGI KOPING PADA PERAWAT DI RAWAT INAP
}

\author{
Zuriati Rahmi ${ }^{1 *}$, Kuntarti $^{2}$
}

1. Program Studi Sarjana Fakultas Ilmu Keperawatan Universitas Indonesia, Depok 16424, Indonesia

2. Fakultas Ilmu Keperawatan Universitas Indonesia, Depok 16424, Indonesia

*E-mail: zuriatirahmi.zr@gmail.com

\begin{abstract}
Abstrak
Masalah tidur merupakan masalah yang sering dialami oleh orang dewasa, termasuk perawat yang bekerja dengan sistem shift di ruang rawat inap. Koping adaptif diperlukan untuk mengatasi masalah tidur tersebut. Penelitian ini bertujuan untuk memeroleh gambaran masalah tidur dan strategi koping perawat dalam mengatasi masalah tidurnya. Penelitian deskriptif ini dilakukan dengan melibatkan 106 perawat rawat inap yang diplih dengan cluster proportional sampling di salah satu Rumah Sakit di Jakarta. Modifikasi Specialised Centres of Research Sleep Questionnaire yang digunakan untuk mengukur masalah tidur, sedangkan mekanisme koping perawat diukur dengan kuesioner yang dikembangkan oleh peneliti. Hasil penelitian menunjukkan bahwa perawat yang bekerja pada unit rawat inap mengalami masalah tidur seperti insomnia $(30,2 \%)$, sleep apnea $(14,2 \%)$, restless legs syndrome $(10,4 \%)$, dan narkolepsi $(10,4 \%)$. Perawat yang mengatasi masalah tidur dengan koping adaptif sebanyak 50,9\%. Pengaturan jadwal shift yang tepat, pengawasan terhadap pelaksanaan jadwal, dan pemilihan koping yang adaptif diharapkan dapat menurunkan prevalensi masalah tidur pada perawat.
\end{abstract}

Kata kunci: insomnia, masalah tidur, mekanisme koping, narkolepsi, perawat, restless legs syndrome, sleep apnea

\begin{abstract}
Sleeping Disorder and Coping Strategy of Clinical Nurses. Sleeping disorder is common problem for adult, including nurses working shift in the ward. Adaptive coping is needed in handling sleeping disorder. This study aimed to identify sleeping disorder of clinical nurse who work in the ward and their coping strategy with that problem. The descriptive method applied to 106 clinical nurses who work at a hospital in Jakarta. A cluster proportional sampling applied to recruit the respondents. Modified Specialised Centres of Research Sleep Questionnaire used to measure sleeping disorder and a questionnaire that was developed by researcher measured nurses' coping to sleeping disorder. Results showed that nurses have problems covered insomnia (30.2\%), sleep apnea (14.2\%), restless legs syndrome (10.4\%), and narcolepsy (10.4\%). Nurses who had adaptive coping were 50.9\%. An appropriate shift schedule, a proper arrangement of the schedule and a chosen adaptive coping may reduce prevalence of sleeping disorder among nurses.
\end{abstract}

Keywords: coping mechanism, narcolepsy, nurse, insomniac restless legs syndrome, sleep apnea, sleeping disorder

\section{Pendahuluan}

Masalah tidur saat ini menjadi isu yang penting di masyarakat terutama bagi perawat (Bartlett, Marshall, Williams \& Grunstein, 2007; Nomura, Yamaok, Nakao \& Yano, 2010). Penelitian terhadap perawat di Rumah Sakit di Norwegia juga menunjukkan bahwa $69,7 \%$ perawat yang bertugas pada ruang perawatan intensif memiliki kualitas tidur yang buruk, dibuktikan dengan hasil skor
Pittsburgh Sleep Quality Index (PSQI) di atas lima (Bjorvatn, et al., 2012; Oyane, et al., 2013). Hal ini berarti lebih dari $50 \%$ perawat mengalami masalah tidur. Sejalan dengan hasil penelitian Chien, Su, Hsieh, Siao, Ling, dan Jou (2013) yang menemukan bahwa di antara staf perawat sebanyak $75,8 \%$ miliki skor PSQI lima atau lebih dan 39,8\% memiliki rasio tidur stabil tidak memadai pada tindakan subjektif. 
Kondisi ini dapat terjadi diantaranya karena tekanan yang sangat besar akibat tuntutan agar para perawat dapat melayani pasien 24 jam, stres, lingkungan yang tidak kondusif, adanya aktivitas selain di tempat tidur, seperti menonton televisi, serta adanya sistem kerja dengan shift (Russeng, Usma \& Saleh, 2007). Masalah tidur yang dialami perawat ternyata berdampak pada kualitas kerja. Secara umum kesulitan tidur dapat mengakibatkan penurunan kinerja, ingatan, dan kemampuan kognitif, serta peningkatan ansietas dan penuruan kesejahteraan (Word, 2006). Hal tersebut dapat memperburuk kinerja perawat dan meningkatkan angka terjadinya kesalahan medis yang berpengaruh terhadap keamanan dan keselamatan pasien (Chien, et al., 2013).

Kondisi penuh tekanan ini mengharuskan individu menggunakan strategi koping, yaitu usaha untuk melakukan tindakan atau strategi mengatasi masalah tidur. Mekanisme koping terbagi menjadi dua, yaitu mekanisme koping adaptif dan maladaptif. Koping yang dapat dilakukan diantaranya memperbaiki kebiasaan tidur, tidur sebentar yaitu sebelum atau pada saat shift malam dan penggunaan obat tidur. ChienMing, Wu, Ming-Hui Hsieh, Ming- Hsiung, \& Feng-Hwa (2003) mengidentifikasi strategi koping yang digunakan oleh mahasiswa yang mengalami masalah tidur, yaitu tidur sesaat atau tidur "kucing" dan/atau tidur selama akhir pekan $(27,5 \%)$, menyesuaikan jadwal tidur $(13,7 \%)$, larut dalam aktivitas yang merangsang tidur seperti latihan relaksasi, mandi air hangat, menghitung "domba" $(11,5 \%)$, dan lainnya seperti minum obat, minum kopi agar tetap terjaga, manajemen stres $(7,4 \%)$.

Bentuk masalah tidur pada tiap individu dan strategi koping yang dilakukan tentu berbeda. Kondisi ini perlu diidentifikasi pada perawat yang bekerja dalam shift agar permasalahan yang mungkin timbuk dapat dicegah. Penelitian ini bertujuan untuk mengidentifikasi gambaran masalah tidur dan strategi koping perawat rawat inap dalam mengatasi masalah tidur.

\section{Metode}

Penelitian deskriptif dengan pendekatan cross-sectional ini melibatkan 106 perawat yang dipilih dengan metode cluster proportional. Penelitian ini dilakukan di sebuah $\mathrm{Ru}-$ mah Sakit di Jakarta Pusat.

Instrumen yang digunakan untuk mengidentifikasi masalah tidur adalah modifikasi Specialised Centres of Research Sleep Questionnaire kemudian diterjemahkan ke dalam Bahasa Indonesia. Kuesioner ini terdiri dari 27 pertanyaan untuk insomnia, sleep apnea, retless legs syndrome, dan narkolepsi. Untuk strategi koping, instrumen yang digunakan dalam penelitian dikembangkan sendiri berdasarkan telaah literature, terdiri dari 23 pernyataan.

Data diperoleh dari kuesioner yang dibagikan ke perawat pelaksana yang bekerja di ruang rawat inap. Setelah data terkumpul dilakukan pengolahan data dengan menggunakan perangkat lunak komputer.

Penelitian ini dilakukan setelah mendapatkan persetujuan dari supervisor dan ijin administrasi dari lokasi penelitian.

\section{Hasil}

Karakteristik Perawat. Karakteristik responden adalah berumur 30 tahun atau kurang $(57,8 \%)$, perempuan $(88,7 \%)$, lama kerja antara 1-10 tahun (67,8\%), unit kerja rawat inap kelas III-II $(49,1 \%)$, dan masalah tidur yang banyak dialami perawat adalah insomnia $(30,2 \%)$. Karakteristik berdasarkan masalah tidur responden dapat dilihat pada Tabel 1.

Strategi Koping. Hasil penelitian menunjukkan bahwa koping adaptif yang diterapkan perawat $(50,9 \%)$. Perilaku koping adaptif yang banyak diterapkan adalah mematikan lampu sebelum tidur $(52,8 \%)$, sedangkan koping maladaptif yang dilakukan adalah menonton TV di atas tempat tidur (17\%). Strategi berdasarkan 

karakteristik responden dapat dilihat pada masalah tidur dapat dilihat pada Tabel 3.

Tabel 2, dan strategi koping berdasarkan

Tabel 1. Masalah Tidur berdasarkan Karakteristik

\begin{tabular}{|c|c|c|c|c|c|c|c|c|}
\hline \multirow{2}{*}{ Karakteristik } & \multicolumn{2}{|c|}{ Insomnia } & \multicolumn{2}{|c|}{ Sleep Apnea } & \multicolumn{2}{|c|}{ Narkolepsi } & \multicolumn{2}{|c|}{ RLS } \\
\hline & $\mathbf{n}$ & $\%$ & $\mathbf{n}$ & $\%$ & n & $\%$ & $\mathbf{n}$ & $\%$ \\
\hline \multicolumn{9}{|l|}{ Usia } \\
\hline$\leq 30$ tahun & 17 & $27.9 \%$ & 8 & $14.3 \%$ & 7 & $12.4 \%$ & 4 & $6.5 \%$ \\
\hline$>30$ tahun & 15 & $34.8 \%$ & 7 & $8.4 \%$ & 4 & $4.6 \%$ & 7 & $14.1 \%$ \\
\hline \multicolumn{9}{|l|}{ Jenis Kelamin } \\
\hline Laki-laki & 3 & $25.0 \%$ & 1 & $8.3 \%$ & 2 & $16.7 \%$ & 0 & $0.0 \%$ \\
\hline Perempuan & 29 & $30.9 \%$ & 14 & $14.9 \%$ & 9 & $9.6 \%$ & 11 & $11.7 \%$ \\
\hline \multicolumn{9}{|l|}{ Lama Kerja } \\
\hline $1-10$ & 18 & $22.1 \%$ & 9 & $15.3 \%$ & 9 & $12.5 \%$ & 5 & $6.9 \%$ \\
\hline $11-20$ & 8 & $55.5 \%$ & 2 & $11.1 \%$ & 1 & $5.6 \%$ & 4 & $27.8 \%$ \\
\hline $21-30$ & 3 & $17.6 \%$ & 3 & $17.6 \%$ & 1 & $11.1 \%$ & 1 & $11.1 \%$ \\
\hline $31-40$ & 3 & $100 \%$ & 1 & $33.3 \%$ & 0 & $0.0 \%$ & 1 & $33.3 \%$ \\
\hline \multicolumn{9}{|l|}{ Unit Kerja } \\
\hline Unit Rawat Inap Kelas III-II & 17 & $32.7 \%$ & 7 & $13.5 \%$ & 3 & $5.8 \%$ & 6 & $11.5 \%$ \\
\hline Unit Rawat Inap Bedah Anak & 0 & $0.0 \%$ & 0 & $0.0 \%$ & 0 & $0.0 \%$ & 0 & $0.0 \%$ \\
\hline Unit Rawat Inap Perinatologi & 2 & $22.2 \%$ & 1 & $11.1 \%$ & 2 & $22.2 \%$ & 0 & $0.0 \%$ \\
\hline Unit Rawat Inap Jantung Terpadu & 4 & $30.8 \%$ & 3 & $23.1 \%$ & 4 & $30.8 \%$ & 3 & $23.1 \%$ \\
\hline Unit Rawat Inap Kelas VVIP & 6 & $27.3 \%$ & 3 & $13.6 \%$ & 2 & $9.1 \%$ & 1 & $4.5 \%$ \\
\hline Unit Rawat Inap Mata & 3 & $37.5 \%$ & 1 & $12.5 \%$ & 0 & $0.0 \%$ & 1 & $12.5 \%$ \\
\hline
\end{tabular}

Tabel 2. Mekanisme Koping berdasarkan Karakteristik

\begin{tabular}{|c|c|c|c|c|}
\hline \multirow{2}{*}{ Karakteristik } & \multicolumn{2}{|c|}{ Maladaptif } & \multicolumn{2}{|c|}{ Adaptif } \\
\hline & $\mathbf{N}$ & $\%$ & $\mathbf{n}$ & $\%$ \\
\hline \multicolumn{5}{|l|}{ Usia } \\
\hline$\leq 30$ tahun & 33 & $54.05 \%$ & 28 & $45.95 \%$ \\
\hline$>30$ tahun & 19 & $46.36 \%$ & 26 & $53.64 \%$ \\
\hline \multicolumn{5}{|l|}{ Jenis Kelamin } \\
\hline Laki-laki & 6 & $50.0 \%$ & 6 & $50.0 \%$ \\
\hline Perempuan & 46 & $48.9 \%$ & 48 & $51.1 \%$ \\
\hline \multicolumn{5}{|l|}{ Lama Kerja (tahun) } \\
\hline $1-10$ & 37 & $45.9 \%$ & 35 & $54.1 \%$ \\
\hline $11-20$ & 6 & $38.9 \%$ & 8 & $61.1 \%$ \\
\hline $21-30$ & 8 & $44.4 \%$ & 9 & $55.6 \%$ \\
\hline $31-40$ & 1 & $33.3 \%$ & 2 & $66.7 \%$ \\
\hline \multicolumn{5}{|l|}{ Unit Kerja } \\
\hline Unit Rawat Inap Kelas III-II & 23 & $44.2 \%$ & 29 & $55.8 \%$ \\
\hline Unit Rawat Inap BedahAnak & 1 & $50.0 \%$ & 1 & $50.0 \%$ \\
\hline Unit Rawat Inap Perinatologi & 4 & $44.4 \%$ & 5 & $55.6 \%$ \\
\hline Unit Rawat Inap Jantung Terpadu & 6 & $46.2 \%$ & 7 & $53.8 \%$ \\
\hline Unit Rawat Inap Kelas VVIP & 14 & $63.6 \%$ & 8 & $36.4 \%$ \\
\hline Unit Rawat Inap Mata & 4 & $50.0 \%$ & 4 & $50.0 \%$ \\
\hline
\end{tabular}


Tabel 3. Mekanisme Koping berdasarkan Masalah Tidur

\begin{tabular}{|c|c|c|c|c|}
\hline \multirow{3}{*}{ Masalah Tidur } & \multicolumn{4}{|c|}{ Mekanisme Koping } \\
\hline & \multicolumn{2}{|c|}{ Adaptif } & \multicolumn{2}{|c|}{ Maladaptif } \\
\hline & $\mathbf{n}$ & $\%$ & $\mathbf{n}$ & $\%$ \\
\hline \multicolumn{5}{|l|}{ Insomnia } \\
\hline Ya & 16 & $50,0 \%$ & 16 & $50,0 \%$ \\
\hline Tidak & 38 & $51,4 \%$ & 36 & $48,6 \%$ \\
\hline \multicolumn{5}{|l|}{ Sleep Apnea } \\
\hline Ya & 7 & $46,7 \%$ & 8 & $53,3 \%$ \\
\hline Tidak & 47 & $51,6 \%$ & 44 & $48,4 \%$ \\
\hline \multicolumn{5}{|l|}{ Narkolepsi } \\
\hline Ya & 5 & $45,5 \%$ & 6 & $54,5 \%$ \\
\hline Tidak & 49 & $51,6 \%$ & 46 & $48,4 \%$ \\
\hline \multicolumn{5}{|l|}{ Restless Legs Syndrome } \\
\hline Ya & 7 & $63,6 \%$ & 4 & $36,4 \%$ \\
\hline Tidak & 47 & $49,5 \%$ & 48 & $50,5 \%$ \\
\hline
\end{tabular}

\section{Pembahasan}

Masalah Tidur Responden. Prevalensi insomnia pada perawat di RS ini jauh lebih rendah dibanding dengan prevalensi insomnia pada perawat di Rumah Sakit di Taiwan yaitu 59\% dari 661 perawat (Chien, et al., 2013).

Perawat sangat berisiko mengalami masalah tidur, hal ini disebabkan karena faktor ansietas, depresi dan bekerja dengan sistem shift (Nursing and Health Sciences, 2011). Shift kerja menyebabkan kelemahan dan kelelahan pada perawat akan berdampak pada kualitas dan kuantitas tidur (Korompeli, Chara, Chrysoula, \& Sourtzi, 2013).

Prevalensi sleep apnea pada orang dewasa mencapai 20\% (Sheldon, Belan, Neill, \& Rowland, 2013). Prevalensi di lapangan tidak jauh berbeda dengan hasil penelitian sebelumnya bahwa perawat yang mengalami sleep apnea $(14,2 \%)$.

Persentase perawat yang mengalami narkolepsi hanya 10,4\%. Hal ini dapat disebabkan karena usia responden yang paling banyak dalam penelitian ini adalah dewasa awal (kurang dari 30 tahun) karena narkolepsi mencapai puncak ketika seseorang berada pada tahap perkembangan dewasa awal.
Restless legs syndrome merupakan gerakan neurologis yang ditandai dengan adanya dorongan kuat pada kaki sehingga menimbulkan sensasi atau rasa tidak nyaman pada kaki (Murray, 2012; Szentkiralyi, Madarasz, \& Novak, 2009). Sebuah penelitian yang dilakukan di Swedia pada 200 perawat perempuan didapatkan hasil bahwa prevalensi restless legs syndrome pada perawat sebesar $11,4 \%$, penelitian tersebut menunjukkan bahwa restless legs syndrome memang lebih sering dialami oleh perempuan dibandingkan dengan laki-laki (Ulfberg, Nystrom, Carter, \& Edling, 2001). Sindrom ini akan lebih sering dialami oleh perempuan yang berusia 45-54 tahun $(10,7 \%)$ (Pekmezovic, Jovic, Stevel, \& Kostic, 2013).

Masalah Tidur berdasarkan Karakteristik Responden Usia. Insomnia $(34,8 \%)$ dan restless legs syndrome $(14,1 \%)$ dialami oleh responden yang berusia lebih dari 30 tahun, sedangkan sleep apnea $(14,3 \%)$ dan narkolepsi $(12,4 \%)$ dialami oleh responden yang berusia kurang dari 30 tahun.

Perawat yang berumur 50 sampai 59 tahun memiliki masalah tidur yang cukup rendah dibandingkan dengan perawat muda (Bjorvatn, et al., 2012). Kondisi ini berbeda dengan hasil penelitian yaitu perawat yang paling banyak mengalami insomnia adalah perawat yang ber- 
umur lebih dari 30 tahun. Hal ini dapat disebabkan karena koping yang diterapkan oleh perawat yang berusia lebih dari 30 tahun belum cukup baik dibanding dengan perawat yang masih muda (Bjorvatn, et al., 2012).

Restless legs syndrome dialami oleh perawat pada usia lebih dari 30 tahun (dewasa menengah). Hal ini sesuai dengan pendapat yang menyatakan bahwa puncak terjadinya restless legs syndrome ketika seseorang berada pada umur dewasa menengah dan meningkat secara signifikan dengan usia.

Sleep apnea dialami oleh perawat yang berusia kurang dari 30 tahun. Jika dikaitkan dengan faktor lingkungan seperti, lingkungan yang bising dapat menjadi penyebab terjadinya sleep apnea pada perawat. Lingkungan yang bising di rumah sakit dapat bersumber dari pasien, keluarga pasien, dan alat-alat medis seperti alat monitor jantung. Perawat muda, yaitu yang berusia 30 tahun atau kurang, yang baru bekerja sebagai perawat belum terbiasa dengan faktor lingkungan di rumah sakit, sehingga menyebabkan perawat mengalami sleep apnea.

Narkolepsi dialami oleh perawat muda. Hal ini sesuai dengan teori yang menyatakan bahwa narkolepsi mencapai puncak ketika seseorang berada pada usia 25 tahun (dewasa awal) yang berkaitan dengan terjadi cataplexy. Cataplexy yaitu keadaan yang ditandai dengan kelemahan otot akibat adanya emosi yang kuat seperti tertawa, marah dan terkejut dan berlangsung selama kurang 2 detik atau bahkan hanya beberapa detik (Rosenberg \& Kim, 2014). Perawat muda memiliki tingkat stres yang tinggi dibandingkan dengan perawat yang telah lama bekerja, sehingga berpengaruh pada kestabilan emosi.

Jenis Kelamin. Prevalensi perempuan yang mengalami insomnia mencapai $66 \%$ dan lakilaki 33\% (Morgantown, 2007). Banyak faktor yang menyebabkan perempuan lebih banyak mengalami insomnia dibandingkan dengan laki-laki, diantaranya menstruasi, genetik, menopause, psikologis, dan beban kerja.

Einollahi dan Izadianmehr (2014) juga melaporkan bahwa perempuan 10 kali lebih berisiko mengalami restless legs synndrome dibandingkan dengan laki-laki. Restless legs syndrome pada perempuan relatif tinggi. Penelitian ini menunjukkan bahwa $90 \%$ dari perempuan dengan gejala vasomotor, yaitu berkeringat pada malam hari selama transisi menopause berkolerasi dengan peningkatan terjadinya restless Legs syndrome.

Sleep apnea lebih banyak dialami oleh perempuan dibanding dengan laki-laki, hal ini berkaitan dengan salah satu penyebab dari sleep apnea adalah obesitas. Tingkat obesitas pada orang dewasa di Amerika Serikat pada tahun 2012 menunjukkan bahwa perempuan $(36,1 \%)$ lebih tinggi dibandingkan dengan laki-laki $(33,5 \%)$ (Obesity Society, 2014). Sebuah penelitian menyebutkan bahwa dalam 20 tahun terakhir terjadi peningkatan angka obesitas di Indonesia terutama pada perempuan, bahkan disebutkan Indonesia menempati urutan ke-10 negara dengan tingkat obesitas tertinggi (Roemling \& Qaim, 2012). Perubahan pola konsumsi makanan dan penurunan aktivitas fisik berkontribusi langsung dengan kondisi ini.

Hasil penelitian menunjukkan bahwa narkolepsi lebih banyak dialami oleh laki-laki. Hasil ini berbeda dengan hasil penelitian yang menyebutkan bahwa kondisi narkolepsi tidak berbeda antar jenis kelamin, hanya saja sering terjadi keterlambatan diagnosis pada perempuan (Won, et al., 2014).

Bagaimanapun hasil penelitian ini tidak dapat diinterpretasi penuh dalam hal jenis kelamin, mengingat jumlah kedua jenis kelamin pada respondennya tidak berimbang, mayoritas perempuan $(88,7 \%)$.

Lama Kerja. Perawat yang mengalami shift malam paling sedikit lima shift malam dalam 
waktu empat tahun melaporkan insomnia yang ditandai dengan susah tidur (Oyane, et al., 2013).

Narkolepsi dialami oleh perawat yang bekerja pada rentang satu sampai 10 tahun. Faktoryang dapat memengaruhi stres kerja adalah masa kerja dengan prevalensi $76,2 \%$ perawat yang bekerja di bawah 10 tahun, 23,8\% pada perawat yang mempunyai masa kerja lebih dari 10 tahun (Russeng, 2007).

Unit Kerja. Insomnia, sleep apnea, restless legs syndrome, dan narkolepsi dialami oleh perawat yang bekerja pada unit rawat inap mata dan rawat inap jantung terpadu yang bukan merupakan kelas VVIP.

Jumlah perawat yang sedikit dan banyaknya tuntutan dari pasien menyebabkan perawat yang bekerja pada unit rawat inap kelas III dan II memiliki tingkat stres dan beban kerja yang lebih tinggi dibandingkan dengan perawat yang bekerja pada unit rawat inap kelas VVIP (Hawati, 2006).

Sementara jika dilihat dari segi fasilitas tempat istirahat, unit kerja rawat inap kelas VVIP memiliki fasilitas tempat istirahat yang lebih baik seperti suhu yang nyaman, lingkungan yang tenang, dan tempat tidur yang nyaman dibandingkan dengan perawat rawat inap kelas III dan II. Dengan demikian, perawat yang bekerja di rawat inap mata dan rawat inap jantung terpadu lebih banyak mengalami masalah tidur dibandingkan dengan perawat rawat inap kelas VVIP.

Strategi Koping Responden. Koping adaptif yang paling banyak dilakukan adalah mematikan lampu kamar sebelum tidur. Mematikan lampu sebelum tidur dianggap sebagai tindakan yang sangat mudah dilakukan oleh seseorang yang mengalami masalah tidur. Sedangkan koping maladaptif yang banyak dilakukan responden adalah menonton televisi di atas tempat tidur.

\section{Strategi Koping berdasarkan Karakteristik Responden}

\section{Usia}

Menurut penelitian yang dilakukan pada perawat yang bertugas di instalasi rawat inap Rumah Sakit di Makasar menunjukkan bahwa perawat yang berumur 41-50 tahun dapat dikatakan lebih memiliki kemampuan yang baik dalam mengatasi masalah tidur. Pekerja dengan umur yang lebih tua semakin mampu menujukkan kematangan jiwa, semakin berfikir rasional, semakin mampu mengendalikan emosi dan menunjukkan kematangan intelektual dan psikologisnya (Russeng, 2007).

\section{Jenis Kelamin}

Strategi yang digunakan oleh laki-laki adalah strategi yang adaptif dan berfokus pada masalah (Melendez, Mayordomo, Sancho, \& Tomas, 2012). Hal ini dapat disebabkan karena laki-laki memiliki kemampuan koping yang berfokus pada masalah dan mampu mengendalikan emosinya.

\section{Lama Kerja}

Semakin lama perawat bekerja, maka akan semakin mudah untuk beradaptasi terhadap suatu masalah. Hal ini membuat perawat yang umurnya cukup tua dan paling lama bekerja memiliki koping yang cukup baik dibandingkan dengan perawat yang masih muda (Bjorvatn et al., 2012).

\section{Unit Kerja}

Pasien yang berada pada perawatan kelas III dan II akan lebih cenderung menuntut perawat untuk melakukan banyak hal dibanding dengan pasien yang berada di perawatan VVIP seperti kecepatan (respon perawat), visit perawat, perhatian dan keramahan perawat (Hawati, 2006). Jika dilihat dari faktor yang memengaruhi koping, maka perawat yang bekerja pada rawat inap kelas III dan II, rawat inap perinatologi dan rawat inap jantung terpadu mampu memandang masalah sebagai tantangan yang positif bagi perawat, sehingga mampu menentukan koping yang efektif. 
Ruang istirahat perawat berpengaruh terhadap strategi koping yang dilakukan. Lingkungan yang nyaman untuk mengatasi masalah tidur adalah lingkungan yang bersih, tenang, sejuk, dan tidak terlalu terang.

\section{Mekanisme Koping berdasarkan Masalah}

Tidur. Individu yang melakukan koping maladaptif bertujuan untuk mengurangi tekanan emosional, bukan untuk menyelesaikan masalah (Morin, Rodrigue \& Ivers, 2003). Sementara bagi individu yang menerapkan koping adaptif disebabkankarena kemampuan dalam memecahkan masalah yang baik. Perawat yang menerapkan koping adaptif dalam mengatasi masalah tidur mampu mencari informasi, menganalisis masalah, dan mengambil strategi yang efektif dalam menyelesaikan masalah tidur. Selain itu, perawat yang menerapkan koping adaptif mendapatkan dukungan sosial yang bagus dari lingkungan sekitar.

Beberapa keterbatasan dalam penelitian ini adalah tidak dilakukannya uji coba instrumen sehingga tidak diketahui reliabiltas dan validitasnya. Penelitian ini juga hanya dilakukan di satu lokasi RS saja, sehingga untuk digeneralisasi pada lokasi yang lebih luas perlu dinilai lagi.

\section{Kesimpulan}

Masalah tidur yang paling banyak dialami oleh perawat adalah insomnia. Perawat melakukan koping adaptif yaitu mematikan lampu sebelum tidur dan melakukan koping maladaptif yaitu menonton televisi di tempat tidur saat menghadapi masalah tidur.

Pihak manajemen RS perlu memberikan pendidikan kesehatan tentang mekanisme koping dan cara mengatur pola tidur yang baik bagi perawat. Pihak rumah sakit diharapkan dapat melakukan modifikasi lingkungan bagi perawat terutama untuk perawat yang bekerja pada shift malam. Pemeriksaan kesehatan secara rutin perlu dilakukan pada seluruh perawat terutama yang bekerja secara shift untuk mendeteksi adanya masalah yang lebih serius dan mempertahankan kesejahteraan mereka.

Penelitian lainnya perlu dilakukan untuk mengidentifikasi lebih lanjut faktor yang berhubungan dengan masalah tidur pada perawat dan mengujicobakan berbagai intervensi untuk mengatasi masalah (HH, AR, INR).

\section{Referensi}

Bartlett, D.J., Marshall, N.S., Williams, A., Grunstein, R.R. (2007). Predictor of primary medical care consultation for sleep disorders. Sleep Med, 9, 857-864 doi: 10.1016/j.sleep. 2007.09.002

Bjorvatn, B., Dale, S., Hogstad-Erikstein, R., Fiske, E., Pallesen, S., \& Waage, S. (2012). Self-reported sleep and health among Norwegian hospital nurses in intensive care units. Nursing in Critical Care, 17(4), 180-8. doi:10.1111/j.1478-5153.2012.00504.x

Chien-Ming, Y., Wu, C., Ming-Hui Hsieh, Ming-Hsiung, L., \& Feng-Hwa, L. (2003). Coping with sleep disturbances among young adults: A survey of first-year college students in Taiwan. Behavioral Medicine, 29(3), 133-8. doi: http://dx.doi.org/10.1080/0896428030959 6066

Chien, P.L., Su, H.F., Hsieh, P.C., Siao, R.Y., Ling, P.Y., \& Jou, H.J. (2013). Sleep quality among female hospital staff nurses. Sleep Disorders, 2013, 6. doi: 10.1155/2013/283490

Einollahi, B. \& Izadianmehr, N. (2014). Restless legs syndrome: A neglected diagnosis. Nephro Urol Mon 6(5): e22009. doi: 10.5812/numon thly.22009

Hawati, D.R.N. (2006). Analisis kepuasan pasien rawat inap dan implikasinya pada peningkatan kualitas pelayanan rumah sakit: Studi kasus Rumah Sakit Agung. (Tesis magister, tidak dipublikasi). Depok, Jawa Barat, Universitas Indonesia. 
Korompeli, A., Chara, T., Chrysoula, L., \&Sourtzi, P. (2013). Sleep disturbance in nursing personnel working shifts. Wiley periodicals inc, 48(1): 45-53. doi: 10.1111/nuf.12005.

Melendez, J.C, Mayordomo, T., Sancho, P.,\& Tomas, J.M. (2012). Coping strategies: gender differences and development throughout life span. The Spanish Journal of Psychology, 15 (3) 1089-1098. Diperoleh dari http://www. ncbi.nlm.nih.gov/pubmed/23156917

Morgantown, A.N.R. (2007). Disertasi: Impact of co-morbid insomnia on health-related quality of life and patient preferences in the primary care setting. West Virginia.

Murray, M. (2012). Stress, anxiety, and insomnia: What the drug companies, won't tell you and your doctor doesn't know. Toronto: Mind Publishing.

Nomura, K., Yamaok, K., Nakao, M., Yano, E. (2010). Social determinants of self reported sleep problems in south korea and taiwan. $J$. Psychosom Res, 69 : 435-440. Nursing and Health Sciences. (2011). 13, 468-474. doi: 10.1016/j.jpsychores.2010.04.014

Obesity Society. (2014). Diperoleh dari http://w ww.obesity.org/resources-for/obesity-statistics. htm

Olvista. (2011). Mengatasi susah tidur dengan sleep hygiene. Diperoleh dari http://olvis ta.com/kesehatan/mengatasi-susah-tidur-denga n-sleep-hygiene/

Oyane, N.M.F., Pallesen, S., Moen, B.E., Åkerstedt, T., \& Bjorvatn, B. (2013). Associations between night work and anxiety, depression, insomnia, sleepiness and fatigue in a sample of Norwegian nurses. Plos One 8(8), e70228. doi: 10.1371/journal.pone.0070228.

Pekmezovic, T.,\& Jovic, J. (2013). Prevalence of restless legs syndrome among adult population in a Serbian district: A community-based study. Eur J Epidemiol , 28:927-930. doi: 10.1007/s10654-013-9857-0
Roemling, C., \& Qaim, M. (2012). Obesity trends and determinants in Indonesia. Appetite, 58(3), 1005-1013. doi: 10.1016/j.appet.2012.02.053

Rosenberg, R., Kim, A.Y. (2014). The awaken survey: Knowledge of narcolepsy among physicians and the general population sleep apnea awareness. Postgrad Med, 126(1), $78-86$.

Russeng, S.S., Usma, M., Saleh, M. (2007). Stres kerja pada perawat di instalasi rawat inap rumah sakit Dr Tadjuddin Chalid Makassar. Media kesehatan masyarakat indonesia, 3(1), $1-56$.

Sheldon, A., Belan, I., Neill, J \& Rowland, S. (2009). Nursing assessment of obstructive sleep apnea in hospitalised adults: A review of risk factors and screening tools. Contemporary Nurse, 34(1), 19-33. doi: http://www. ncbi.nlm.nih.gov/pubmed/20230169

Szentkiralyi, A., Madarasz, C.Z., Novak, M. (2009). Sleep disorders: Impact on daytime functioning and quality of life. Pharmacoeconomics Outcomes Res. 9(1) : 4964. doi: 10.1586/14737167.9.1.49.

Ulfberg, J., Nystrom, B., Carter, N \& Edling, C. (2001). Restless legs syndrome among working-aged women. Eur Neurol, 46:17-19. doi:10.1159/000050750)

Won, C., Mahmoudi, M., Qin, L., Purvis, T., Mathur, A., \& Mohsenin, V. (2014). The impact of gender on timeliness of narcolepsy diagnosis. J Clin Sleep Med, 10(1), 89-95. doi: $10.5664 / \mathrm{jcsm} .3370$

Word, C. A. (2006). Sleep quality of college students and its relationship to coping styles and well-being (Order No. 3259730). Available from ProQuest Dissertations \& Theses Global. (305318583). Diperoleh dari http://search.proquest.com/docview/30531858 3 ? accountid $=17242$ 